\title{
Effects of feeding a Saccharomyces cerevisiae In fermentation prototype on performance, carcass characteristics, and liver abscess prevalence of beef heifers at a commercial feedlot
}

\author{
M. F. Scott, ${ }^{* 1}$ PAS, K. L. Dorton, ${ }^{*}$ D. L. Henry, ${ }^{*}$ C. R. Belknap, ${ }^{\star}$ PAS, D. L. Hanson, ${ }^{*}$ and B. E. Depenbusch† \\ *Diamond V, Cedar Rapids, IA 52404; and †Innovative Livestock Services Inc., Great Bend, KS 67530
}

\begin{abstract}
Animal agriculture continues to look for new, non-antibiotic feed solutions that can be used in conventional and natural feedlot systems to help improve cattle health and performance. Therefore, crossbred heifers $(\mathrm{n}=1,495$; $359 \pm 10.75 \mathrm{~kg} ; 20$ pens total) were used in a randomized complete block design study at a commercial feedlot to determine the effects of a proprietary Saccharomyces cerevisiae fermentation prototype on performance, carcass characteristics, and liver abscess prevalence when monensin, tylosin, and direct-fed microbials were not included in the diet. Heifers were fed a diet containing (1) monensin, tylosin, and a direct-fed microbials (PC) or (2) a Saccharomyces cerevisiae fermentation prototype (PRT; NaturSafe, Diamond V, Cedar Rapids, IA) at $18 \mathrm{~g} /$ head daily without PC. Diets were fed twice daily with heifers receiving half of the daily dose of treatment in the TMR at each feeding. Pen BW were collected on d 0 and before slaughter. Daily measurements recorded while cattle were in the feedlot included feed intake, morbidity, and mortality. Cattle were shipped to slaughter on d 125 and 146 (5 pens per treatment per day). Carcass data collected included HCW, DP, QG, YG, KPH, rib fat thickness, LM area, marbling score, and liver abscess scores. Data were analyzed with the MIXED procedure (continuous) and GLIMMIX procedure (categorical) of SAS. Treatments were similar $(P \geq 0.16)$ for final BW (580 vs. $580 \mathrm{~kg})$, ADG (1.64 vs. $1.63 \mathrm{~kg} / \mathrm{d}), \mathrm{G}: \mathrm{F}$ (0.159 vs. $0.156 \mathrm{~kg} / \mathrm{kg}$ ), HCW (366 vs. $367 \mathrm{~kg}$ ), other carcass characteristics, morbidity (0.3 vs. $0.0 \%)$, and mortality $(0.77$ vs. $0.70 \%)$. Heifers fed PRT had a numerically lower $(P=0.27)$ prevalence of liver abscesses with fewer livers having less severe (i.e., A-) abscesses. Replacing monensin, tylosin, and directfed microbials in conventional feedlot diets with NaturSafe
\end{abstract}

${ }^{1}$ Corresponding author: markfscott@msn.com resulted in similar growth performance, carcass characteristics, and liver abscess prevalence in feedlot cattle.

Key words: beef heifer, large pen, performance, Saccharomyces cerevisiae fermentation prototype

\section{INTRODUCTION}

The Veterinary Feed Directive was implemented by the Food and Drug Administration to minimize the use of antibiotics in animal feed that are similar to those that have application in human medicine. Beginning in January 2017, feed grade antibiotics, such as tylosin, cannot be used unless a veterinarian prescription is provided (US Food and Drug Administration, 2015). Tylosin is used in the beef industry to help minimize abscesses in the liver and has been shown to decrease the growth of Fusobacterium necrophorum and Trueperella (Arcanobacterium) pyogenes (the main cause of liver abscesses) in the rumen (Nagaraja and Chengappa, 1998).

Other conventional feed technologies commonly used in beef feedlot diets are monensin and bacterial (Lactobacillus and Propionibacterium) direct-fed microbials (DFM). Monensin has been shown to improve feed efficiency, reduce the likelihood of feedlot bloat, and play a role in controlling coccidiosis (Long and Jeffers, 1982; Stock et al., 1995; Cheng et al., 1998; Duffield et al., 2012). Direct-fed microbials have had variable results on rumen health and cattle performance when used in feedlot diets (Brashears et al., 2003; Elam et al., 2003; Peterson et al., 2007). Unlike tylosin, the Veterinary Feed Directive does not affect ionophores or DFM.

Universities and companies within animal agriculture continue to research and develop new, non-antibiotic feed solutions that can be used in conventional and natural feedlot systems to help improve cattle health and performance. Therefore, this study was designed to evaluate the effects of a proprietary Saccharomyces cerevisiae fermentation prototype on the performance, health, carcass charac- 
teristics, and prevalence of liver abscesses in feedlot cattle when monensin, tylosin, and DFM were not included in the diet.

\section{MATERIALS AND METHODS}

\section{Experimental Design}

Animals were handled in compliance with applicable local regulations and in accordance with the Guide for Care and Use of Agricultural Animals in Research and Teaching (FASS, 2010).

Crossbred heifers $(\mathrm{n}=1,495 ; 359 \pm 3.4 \mathrm{~kg})$ were received at a Central Kansas feedyard in May 2015. Heifers were purchased from 2 sale barns (Salina, KS, $\mathrm{n}=255$ head; and Pratt, KS, $\mathrm{n}=183$ head) and one backgrounding facility (Central Kansas, $\mathrm{n}=1,057$ head), where the heifers grazed wheat pasture. On arrival, heifers were allowed ad libitum access to fresh water and long-stemmed hay.

On the day after arrival, heifers were individually weighed, processed, and randomly sorted by source into pens ( 5 animals per pen until the desired head count was achieved in each pen; 67 or 80 head per pen). Pens per replicate ( 2 adjacent pens of similar size and head count; 10 replicates total) were assigned to 1 of 2 treatments. A 2 -tailed statistical power analysis for ADG [power $(1-\beta)$ $=0.8, \alpha=0.05, \mathrm{SD}=0.136]$ showed 10 replicates per treatment were necessary to detect an expected difference in $\mathrm{ADG}$ of $0.181 \mathrm{~kg}$. Treatments were added to the diet using a micro-ingredient weigh system $(\mathrm{mg} / \mathrm{head}$ basis; Micro Beef Technologies, Amarillo, TX) and consisted of a diet containing a combination of standard industry technologies (PC), including monensin (300 mg/head daily; Rumensin, Elanco Animal Health, Greenfield, IN), tylo$\sin (90 \mathrm{mg} /$ head daily; Tylovet, Huvepharma, Peach Tree, GA), and a DFM (50 mg/head daily; Bovamine Defend, Nutrition Physiology Company, Overland Park, KS) or a diet containing $18 \mathrm{~g} /$ head daily of a Saccharomyces cerevisiae fermentation prototype (PRT; NaturSafe, Diamond V, Cedar Rapids, IA) without monensin, tylosin, or the DFM. Saccharomyces cerevisiae fermentation prototype is a fermentation prototype containing proprietary levels of functional metabolites such as peptides, organic acids, and antioxidants. All pens received $0.5 \mathrm{mg}$ of melengestrol acetate (MGA, Zoetis Animal Health, Exton, PA) in the diet

Table 1. Ingredient and calculated nutrient composition of corn-based diets fed to yearling heifers

\begin{tabular}{|c|c|c|c|c|}
\hline \multirow[b]{2}{*}{ Item } & \multicolumn{4}{|c|}{ Basal diet } \\
\hline & Starter & Step 2 & Step 3 & Finisher \\
\hline \multicolumn{5}{|l|}{ Ingredient, \% DM basis } \\
\hline Steam-flaked corn & 30.2 & 45.8 & 58.6 & 66.1 \\
\hline Wet distillers grain with solubles & 22.2 & 19.5 & 18.0 & 18.0 \\
\hline Alfalfa hay & 38.0 & 25.0 & 13.0 & 0.0 \\
\hline Mixed hay & 0.0 & 0.0 & 0.0 & 4.0 \\
\hline Corn silage & 7.0 & 7.0 & 5.0 & 4.0 \\
\hline Tallow & 0.0 & 0.0 & 1.5 & 2.9 \\
\hline Liquid supplement ${ }^{1}$ & 2.6 & 2.7 & 3.9 & 5.0 \\
\hline \multicolumn{5}{|l|}{ Nutrient composition } \\
\hline $\mathrm{DM}, \%$ & 55.8 & 57.0 & 59.1 & 60.3 \\
\hline $\mathrm{CP}, \%$ & 17.9 & 16.4 & 15.7 & 15.1 \\
\hline Ether extract, \% & 4.50 & 4.57 & 6.12 & 7.60 \\
\hline Calcium, \% & 0.94 & 0.78 & 0.80 & 0.83 \\
\hline Phosphorus, \% & 0.37 & 0.37 & 0.37 & 0.37 \\
\hline Potassium, \% & 0.98 & 0.82 & 0.66 & 0.56 \\
\hline Sulfur, \% & 0.30 & 0.27 & 0.24 & 0.22 \\
\hline $\mathrm{NE}_{\mathrm{m}}, \mathrm{Mcal} / \mathrm{kg}$ & 1.83 & 2.01 & 2.21 & 2.36 \\
\hline $\mathrm{NE}_{\mathrm{g}}, \mathrm{Mcal} / \mathrm{kg}$ & 1.17 & 1.32 & 1.50 & 1.63 \\
\hline
\end{tabular}

${ }^{1}$ Positive control diet contained monensin (Rumensin, Elanco Animal Health, Greenfield, IN), tylosin (Tylovet, Huvepharma, Peach Tree, GA), and a direct-fed microbial (Bovamine Defend, Nutrition Physiology Company, Overland Park, KS) at 300, 90, and $50 \mathrm{mg} / \mathrm{animal}$ daily, respectively. Prototype (PRT) diets were formulated to provide $18 \mathrm{~g}$ of a prototype Saccharomyces cerevisiae fermentation prototype (NaturSafe, Diamond V, Cedar Rapids, IA) per heifer daily throughout the trial. Both treatment groups also received $0.5 \mathrm{mg}$ of melengestrol acetate (Zoetis Animal Health) per heifer daily throughout the trial and $250 \mathrm{mg}$ of ractopamine hydrochloride (Zoetis Animal Health) per heifer daily during the last $28 \mathrm{~d}$ on feed. 
daily and $250 \mathrm{mg}$ ractopamine hydrochloride (Actogain, Zoetis Animal Health) in the diet daily during the last 28 $\mathrm{d}$ on feed.

During processing, heifers were uniquely identified with numbered tags in both ears. The right ear tag contained the lot number and was color coded to treatment (white or red for PC and PRT, respectively). All feedlot personnel were blinded to treatment. The left ear tag contained the lot number and animal ID number. Heifers were vaccinated for infectious bovine rhinotracheitis and parainfluenza-3 using Pyramid 4 cattle vaccine (Boehringer Ingelheim Vetmedica Inc., Ridgefield, CT). In addition, heifers received an injection for internal parasites (Dectomax, Zoetis Animal Health), an oral dose of dewormer (Safeguard, Merck Animal Health, De Soto, KS), and a growth implant (Revalor-IH containing $80 \mathrm{mg}$ of trenbolone acetate $+8 \mathrm{mg}$ of estradiol, Merck Animal Health) under the skin in the posterior aspect of the ear. Approximately $63 \mathrm{~d}$ after the initial growth implant and $74 \mathrm{~d}$ before slaughter, heifers were revaccinated for infectious bovine rhinotracheitis and parainfluenza-3 (Bovi Shield Gold IBR-BVD, Zoetis Animal Health), vaccinated with an autogenous Foot Rot vaccine (Newport Laboratories Inc., Worthington, MN), and reimplanted (Revalor 200 containing $200 \mathrm{mg}$ of trenbolone acetate $+20 \mathrm{mg}$ of estradiol, Merck Animal Health).
Heifers were housed in 20 soil-surfaced pens providing $36.6 \mathrm{~cm}$ of bunk space and $21.5 \mathrm{~m}^{2}$ of pen space per heifer. Each pen contained an earthen mound and water fountain that supplied fresh well water. Feed was delivered using horizontal mixing auger trucks, and mixing uniformity was assessed before and during the study (11 assessments total). Heifers received 3 step-up diets $(\sim 8 \mathrm{~d} /$ diet $)$ before their final finishing diet (Table 1). Pens within a block were treated the same as it pertains to transitioning onto the finishing diet. Diets were fed twice daily at approximately 0830 and $1350 \mathrm{~h}( \pm 20 \mathrm{~min})$. Feed bunks were managed so that only a trace amount of feed was left in the bunk at each feeding. All treatment feed additives were stored under manufacturer-recommended conditions, and the amount fed was adjusted monthly, or sooner if necessary, to account for variation in ingredient DM and cattle intakes. Actual formulated intakes were achieved for each feed additive.

Trained animal caretakers individually observed heifers within each pen daily. Heifers were observed for lameness, anorexia, dull eyes, labored breathing, droopy ears, coughing, diarrhea, nasal discharge, and general overall well-being. Heifers experiencing any clinical signs were removed and further evaluated in the hospital pen. Once restrained in the hospital observation chute, BW, rectal body temperature, and lung score were determined. Heif-

Table 2. Effects of a Saccharomyces cerevisiae fermentation prototype (PRT) on growth performance of yearling beef heifers

\begin{tabular}{|c|c|c|c|c|}
\hline Item & $\mathrm{PC}^{1}$ & $\mathrm{PRT}^{2}$ & SEM & $P$-value \\
\hline Heifers (pens), no. & $748(10)$ & $747(10)$ & $N / A^{3}$ & N/A \\
\hline Days on feed & 136 & 136 & $N / A$ & $N / A$ \\
\hline Bunk space, $\mathrm{cm} /$ head & 36.6 & 36.6 & N/A & $N / A$ \\
\hline Pen space, $\mathrm{m}^{2} /$ head & 21.5 & 21.5 & $N / A$ & $N / A$ \\
\hline \multicolumn{5}{|l|}{ Live performance ${ }^{4}$} \\
\hline Initial BW, kg & 358.3 & 359.7 & 3.40 & 0.33 \\
\hline Final $\mathrm{BW},{ }^{5} \mathrm{~kg}$ & 579.7 & 580.6 & 3.20 & 0.80 \\
\hline DMI, kg/d & 10.3 & 10.4 & 0.15 & 0.09 \\
\hline$A D G, \mathrm{~kg} / \mathrm{d}$ & 1.64 & 1.63 & 0.020 & 0.73 \\
\hline $\mathrm{G}: \mathrm{F}, \mathrm{kg} / \mathrm{kg}$ & 0.159 & 0.156 & 0.0018 & 0.16 \\
\hline \multicolumn{5}{|c|}{ Yield-adjusted performance ${ }^{6}$} \\
\hline $\mathrm{BW}, \mathrm{kg}$ & 574.3 & 575.6 & 9.30 & 0.64 \\
\hline$A D G, k g / d$ & 1.59 & 1.59 & 0.019 & 0.94 \\
\hline $\mathrm{G}: \mathrm{F}$ & 0.155 & 0.153 & 0.0028 & 0.20 \\
\hline
\end{tabular}

${ }^{1}$ Positive control (PC) diet contained monensin (Rumensin, Elanco Animal Health, Greenfield, IN), tylosin (Tylovet, Huvepharma, Peach Tree, GA), and a direct-fed microbial (Bovamine Defend, Nutrition Physiology Company, Overland Park, KS) at 300, 90, and $50 \mathrm{mg} /$ animal daily, respectively.

2Prototype (PRT) diet contained S. cerevisiae fermentation prototype (NaturSafe, Diamond V, Cedar Rapids, IA) at $18 \mathrm{~g} /$ animal daily and no monensin, tylosin, or direct-fed microbial.

${ }^{3} \mathrm{~N} / \mathrm{A}=$ not applicable.

${ }^{4}$ Live performance included dead and removed animals.

${ }^{5}$ Final BW pencil shrunk $4 \%$.

${ }^{6}$ Yield-adjusted BW calculated by dividing HCW by a common dressing yield of $63.75 \%$. 
ers were then treated based on the clinical signs observed in the pen and the results from the chute side diagnostics according to the treatment protocols established by the consulting veterinarian. In general, heifers were treated and returned to their home pen on the same day. However, in some cases, the heifer was kept in the hospital recovery pen until it was well enough to be returned to its home pen. Heifers that did not respond to therapy were pulled from the trial, labeled as a chronic (i.e., railer), held until drug withdrawal requirements were met, and shipped to a rendering facility. The feedlot veterinarian performed necropsies on all heifers that died to determine cause of death.

Heifers were on trial for 125 to 146 d before slaughter. The amount of feed offered was recorded daily. Heifers were weighed by pen on a large platform scale (approximately $3.5 \mathrm{~m} \times 27.5 \mathrm{~m}$ ) on $\mathrm{d} 0$ and the morning before shipment. On the day of slaughter, heifers were transported approximately $233 \mathrm{~km}$ to a commercial abattoir located in Holcomb, Kansas. Heifers were slaughtered on 2 separate shipping dates approximately 3 wh apart (d 125 and 146 for group 1 and 2, respectively). Five pens per treatment were shipped on each shipping date. Heifers were maintained within their pen during shipping and at the abattoir. Heifers were processed by pen, and trained personnel at the abattoir collected carcass measurements using a video image analysis system. Average carcass weight, DP, USDA QG, USDA YG, KPH, 12th rib fat thickness, LM area, and marbling score were collected on each carcass at the abattoir. A calculated YG was determined using the following equation (Boggs and Merkel, 1993):

$$
\begin{aligned}
& \text { Yield grade }=2.50+(6.35 \times \text { fat thickness, } \mathrm{cm}) \\
& \begin{aligned}
-\left(2.06 \times \mathrm{LM} \text { area }, \mathrm{cm}^{2}\right)+(0.2 \times \mathrm{KPH}, \%) \\
+(0.0017 \times \mathrm{HCW}, \mathrm{kg}) .
\end{aligned}
\end{aligned}
$$

Fecal swab samples and subiliac lymph nodes were also collected during slaughter to be analyzed for food-borne pathogens. However, this is reported elsewhere (Feye et al., 2016). Liver scores were also collected on each carcass using trained personnel from Garden City Community College (Garden City, KS). The liver was evaluated after evisceration using the liver abscess classification method developed by Elanco Animal Health (Brown et al., 1975). Livers were scored as follows:

(1) O - a normal healthy liver with no abscesses;

(2) $\mathrm{A}^{-}-1$ or 2 small abscesses or inactive scars, which are generally under $2.54 \mathrm{~cm}$ in diameter, with the remaining liver appearing healthy;

(3) A - 1 or 2 large abscesses, or several small abscesses, with the remaining liver appearing healthy; or

(4) $\mathrm{A}^{+}$- multiple large abscesses present, along with inflammation of liver tissue surrounding the abscess. Often, portions of the diaphragm are adhered to the surface of the liver and have to be trimmed to separate the liver from the carcass.

\section{Statistical Analysis}

Growth performance and carcass characteristics (continuous data) were analyzed using the MIXED procedure of SAS (9.3, SAS Institute Inc., Cary, NC). Pen was considered the experimental unit. The model included treatment as the fixed effect, block as the random effect to explicitly account for the lack of independence among pens within block, and treatment $\times$ block as the error term. The LSMEANS and corresponding SEM were calculated from model outputs. Categorical data, including binary health and carcass QG, YG, and liver abscess outcomes, were modeled using the GLIMMIX procedure of SAS using a binomial and ordinal distribution, respectively. The Link $=$ Logit option was used in the model statement, and LSMEANS and corresponding SEM were calculated from model outputs following back transformation from

Table 3. Effects of a Saccharomyces cerevisiae fermentation prototype (PRT) on animal health characteristics of yearling heifers

\begin{tabular}{lrrrc} 
Item & PC $^{1}$ & PRT $^{2}$ & SEM & P-value \\
\hline Morbidity, \% & & & & \\
$\quad$ Respiratory & 2.9 & 2.0 & 0.74 & 0.26 \\
Digestive & 0.0 & 0.0 & $\mathrm{~N}^{3} \mathrm{~A}^{3}$ & $\mathrm{~N} / \mathrm{A}$ \\
$\quad$ Foot rot and lameness & 17.5 & 21.8 & 3.15 & 0.06 \\
Other & 0.3 & 0.0 & 0.19 & 0.98 \\
Pull rate, \% & & & & \\
1st pull & 19.0 & 22.1 & 3.09 & 0.14 \\
2nd pull & 1.7 & 1.6 & 0.51 & 0.85 \\
$\quad$ 3rd pull & 0.3 & 0.13 & 0.19 & 0.67 \\
Mortality, \% & & & & \\
$\quad$ Respiratory & 0.40 & 0.13 & 0.23 & 0.52 \\
Digestive & 0.00 & 0.27 & 0.19 & 0.98 \\
$\quad$ Other & 0.40 & 0.27 & 0.23 & 0.73 \\
$\quad$ Total & 0.80 & 0.67 & 0.33 & 0.81 \\
Chronic (railer), ${ }^{4} \%$ & 0.26 & 0.77 & 0.35 & 0.19 \\
\hline
\end{tabular}

${ }^{1}$ Positive control (PC) diet contained monensin (Rumensin, Elanco Animal Health, Greenfield, IN), tylosin (Tylovet, Huvepharma, Peach Tree, GA), and a directfed microbial (Bovamine Defend, Nutrition Physiology Company, Overland Park, KS) at 300, 90, and $50 \mathrm{mg} /$ animal daily, respectively.

2Prototype (PRT) diet contained S. cerevisiae fermentation prototype (NaturSafe, Diamond V, Cedar Rapids, IA) at $18 \mathrm{~g} /$ animal daily and no monensin, tylosin, or direct-fed microbial.

${ }^{3} \mathrm{~N} / \mathrm{A}=$ not applicable.

${ }^{4}$ Chronic (railer) $=$ heifers that were removed from the study because they did not respond to therapy. 
the logit scale. Data were considered significant at $P \leq$ 0.05 and a trend at $0.05>P \leq 0.10$.

\section{RESULTS AND DISCUSSION}

\section{Performance}

Growth performance data are in Table 2. Heifers fed PRT tended $(P=0.09)$ to consume $0.1 \mathrm{~kg}$ more feed per day. However, ADG, G:F, and final BW were not different $(P \geq 0.16)$ between treatments. Morbidity and mortality results are in Table 3 . No significant $(P \geq 0.16)$ differences were observed between treatments.

Heifers were fed a finishing diet that contained $66 \%$ steam-flaked corn, $18 \%$ wet distillers grains plus solubles, $4.0 \%$ mixed hay, $4.0 \%$ corn silage, and $2.9 \%$ tallow. Heifers receiving PC consumed an average of $10.3 \mathrm{~kg}$ of DM daily, which corresponds to an average consumption of 29 $\mathrm{mg} / \mathrm{kg}$ monensin, $8.7 \mathrm{mg} / \mathrm{kg}$ tylosin, and $4.9 \mathrm{mg} / \mathrm{kg}$ DFM. The positive DMI response for heifers supplemented with PRT compared with PC may be the result of heifers not receiving monensin and tylosin in the diet, a change in ruminal kinetics due to supplemental fat and monensin in heifers fed the PC diet (Clary et al., 1993), or a more stable rumen environment due to PRT (Brainard et al., 2014). Previous research with the combination of monensin and tylosin in similar finishing diets to those in this study did not improve DMI in heifers or steers compared with a diet without these additives, but the combination did show a $4.1 \%$ improvement in G:F in steers (Depenbusch et al., 2008; Meyer et al., 2013). Research reported by Elanco Animal Health (2012) showed that the combination of monensin and tylosin reduced DMI by $5 \%$. In addition, Duffield et al. (2012) summarized 64 trials that were conducted over the last $40 \mathrm{yr}$ and found that monensin decreased DMI by 3\%. Duffield et al. (2012) noted that the effect of monensin on feed conversion has decreased in recent years. In fact, they estimated that the improvement in DM conversion has decreased from $6 \%$ observed in the 1970 s and 1980 s to about $3 \%$ in the last 2 decades. However, unlike the Elanco data and the summary data reported by Duffield et al. (2012), feed conversions were not significantly different in the current study when monensin and tylosin were fed.

Table 4. Effects of a Saccharomyces cerevisiae fermentation prototype (PRT) on carcass characteristics of yearling beef heifers

\begin{tabular}{|c|c|c|c|c|}
\hline Item & $\mathrm{PC}^{1}$ & $\mathrm{PRT}^{2}$ & SEM & $P$-value \\
\hline Carcasses (pens), no. & $740(10)$ & $735(10)$ & $N / A^{3}$ & N/A \\
\hline $\mathrm{HCW}, \mathrm{kg}$ & 366 & 367 & 2.68 & 0.58 \\
\hline $\mathrm{DP}, \%$ & 63.13 & 63.20 & 0.23 & 0.57 \\
\hline USDA QG, \% & & & N/A & 0.51 \\
\hline Prime & 1.0 & 0.4 & & \\
\hline Choice & 63.9 & 61.8 & & \\
\hline Select & 33.5 & 36.9 & & \\
\hline No roll & 1.6 & 1.0 & & \\
\hline USDA YG, \% & & & N/A & 0.48 \\
\hline YG 1 & 7.7 & 7.8 & & \\
\hline YG 2 & 34.1 & 38.0 & & \\
\hline YG 3 & 45.8 & 43.7 & & \\
\hline YG 4 & 11.9 & 9.8 & & \\
\hline YG 5 & 0.5 & 0.8 & & \\
\hline Calculated YG 4 & 3.12 & 3.05 & 0.060 & 0.21 \\
\hline $\mathrm{KPH}, \%$ & 2.11 & 2.11 & 0.017 & 0.65 \\
\hline 12th rib fat thickness, $\mathrm{cm}$ & 1.24 & 1.22 & 0.03 & 0.73 \\
\hline LM area, $\mathrm{cm}^{2}$ & 89.55 & 90.52 & 0.60 & 0.28 \\
\hline Marbling score ${ }^{5}$ & 420 & 412 & 4.09 & 0.18 \\
\hline
\end{tabular}

${ }^{1}$ Positive control (PC) diet contained monensin (Rumensin, Elanco Animal Health, Greenfield, IN), tylosin (Tylovet, Huvepharma, Peach Tree, GA), and a direct-fed microbial (Bovamine Defend, Nutrition Physiology Company, Overland Park, KS) at 300, 90, and 50 mg/animal daily, respectively.

2Prototype (PRT) diet contained S. cerevisiae fermentation prototype (NaturSafe, Diamond V, Cedar Rapids, IA) at $18 \mathrm{~g} / \mathrm{animal}$ daily and no monensin, tylosin, or direct-fed microbial.

${ }^{3} \mathrm{~N} / \mathrm{A}=$ not applicable.

${ }^{4}$ Calculated $\mathrm{YG}=2.5+(6.35 \times$ adjusted fat thickness, $\mathrm{cm})+(0.20 \times \mathrm{KPH} \%)-(2.06 \times \mathrm{LM}$ area, $\left.\mathrm{cm}^{2}\right)+(0.0017 \times \mathrm{HCW}, \mathrm{kg})$.

${ }^{5} 400=$ Small 00; $500=$ Modest $00 ; 600=$ Moderate 00. 
Table 5. Effects of a Saccharomyces cerevisiae fermentation prototype (PRT) on liver abscesses of yearling heifers

\begin{tabular}{lcccc} 
Item & PC $^{1}$ & PRT $^{2}$ & SEM & P-value \\
\hline Carcasses (pens), no. & $740(10)$ & $735(10)$ & N/A & N/A \\
Liver abscesses, ${ }^{3} \%$ & 20.9 & 16.3 & N/A & 0.27 \\
$\mathrm{~A}^{-}$ & 7.5 & 3.7 & & \\
$\mathrm{~A}^{+}$ & 5.3 & 3.9 & & \\
$\mathrm{~A}^{+}$ & 8.1 & 8.7 & & \\
Contamination, \% $_{\text {Cirrhosis, \% }}$ & 7.6 & 8.3 & 1.21 & 0.66 \\
Telangiectasis, \% & 0.0 & 0.0 & $\mathrm{~N} / \mathrm{A}$ & $\mathrm{N} / \mathrm{A}$ \\
Flukes, \% & 0.0 & 0.0 & $\mathrm{~N} / \mathrm{A}$ & $\mathrm{N} / \mathrm{A}$ \\
\end{tabular}

${ }^{1}$ Positive control (PC) diet contained monensin (Rumensin, Elanco Animal Health, Greenfield, IN), tylosin (Tylovet, Huvepharma, Peach Tree, GA), and a direct-fed microbial (Bovamine Defend, Nutrition Physiology Company, Overland Park, KS) at 300, 90, and 50 mg/animal daily, respectively.

${ }^{2}$ Prototype (PRT) diet contained S. cerevisiae fermentation prototype (NaturSafe, Diamond V, Cedar Rapids, IA) at $18 \mathrm{~g} / \mathrm{animal}$ daily and no monensin, tylosin, or direct-fed microbial.

${ }^{3} \mathrm{~N} / \mathrm{A}=$ not applicable.

${ }^{4}$ Livers were scored using methods described by Brown et al. (1975).

\section{Carcass Characteristics}

No differences were observed between treatments for any of the carcass characteristics measured $(P \geq 0.18$; Table 4). Although there are no other studies examining the effects of PRT on carcass characteristics in beef cattle, studies with other Saccharomyces cerevisiae fermentation products (SCFP) have shown beneficial effects. In a recent meta-analysis, supplementation of SCFP (Original YC, XP, and XPC, Diamond V) to beef cattle fed conventional diets resulted in an improvement in carcass quality (more low choice and less select carcasses; Wagner et al., 2016). One study included in this meta-analysis was a study by Swyers et al. (2014). In this study, they looked at the interactive effects of monensin and SCFP (Original XP). Although not statistically different, cattle fed a diet supplemented with SCFP that did not contain monensin had numerically more choice carcasses (30 and $55 \%$, respectively) and fewer select carcasses (53 and 33\%, respectively) when compared with cattle fed a diet with monensin and no SCFP. Cattle fed a diet containing both monensin and SCFP had similar choice (58\%) and select (38\%) carcasses to those fed SCFP alone. The results from the current study suggest that removing monensin and tylosin from finishing diets fed to heifers and replacing with PRT would yield similar carcass characteristics.

\section{Liver Abscesses}

The total prevalence of liver abscesses was similar $(P$ $=0.27$ ) between treatments (Table 5). However, heifers fed PRT had fewer total liver abscesses, specifically less severe (i.e., A-) abscesses. Reinhardt and Hubbert (2015) found that the degree of grain processing and the subsequent increase in the rate of ruminal starch fermentation and potential risk of acidosis was not a primary factor in formation or reduction of liver abscesses. Roughage level and form had a much greater effect on liver abscesses than did grain source or degree of processing. Previous research summarized by Laudert and Vogel (2004) showed that tylosin reduced liver abscesses by $73 \%$ (7.48 vs. $27.90 \%$ for tylosin and no tylosin, respectively). Wagner et al. (2016) revealed that cattle supplemented with other SCFP products (Original YC, XP, and XPC) tended to have a lower liver abscess prevalence than those fed a conventional diet that contained tylosin.

\section{IMPLICATIONS}

Replacing monensin, tylosin, and bacterial (Lactobacillus and Propionibacterium) DFM in conventional feedlot diets with NaturSafe (PRT) resulted in similar growth performance, carcass characteristics, and liver abscess prevalence in yearling fed heifers. NaturSafe (PRT) is a potential fit in a natural yearling feedlot production system and may offset some of the growth performance losses normally observed when monensin and tylosin are removed from a conventional production system.

\section{ACKNOWLEDGMENTS}

The authors acknowledge funding support from Diamond V (Cedar Rapids, IA). 


\section{LITERATURE CITED}

Boggs, D. L., and R. A. Merkel. 1993. Beef carcass evaluation, grading, and pricing. Page 105 in Live Animal Carcass Evaluation and Selection Manual. D. L. Boggs and R. A. Merkel, ed. Kendall Hunt Publ. Co., Dubuque, IA.

Brainard, A., V. Nsereko, I. Yoon, J. Butler, and M. Scott. 2014. Effects of Saccharomyces cerevisiae fermentation products on fiber digesting and lactate utilizing rumen bacteria at neutral and low $\mathrm{pH}$ in vitro. Page 30 (P115 Abstr.) in Proc. Symp. Gut Health Prod. Food Anim., St. Louis, MO. FASS Inc., Champaign, IL.

Brashears, M. M., M. L. Galyean, G. H. Loneragan, J. E. Mann, and K. Killinger-Man. 2003. Prevalence of Escherichia coli O157:H7 and performance by beef feedlot cattle given Lactobacillus direct-fed microbials. J. Food Prot. 66:748-754.

Brown, H., R. F. Bing, H. P. Grueter, J. W. McAskill, C. O. Cooley, and R. P. Rathmacher. 1975. Tylosin and chlortetracycline for the prevention of liver abscesses, improved weight gains and feed efficiency in feedlot cattle. J. Anim. Sci. 40:207-213.

Cheng, K. J., T. A. McAllister, J. D. Popp, A. N. Hristov, Z. Mir, and H. T. Shin. 1998. A review of bloat in feedlot cattle. J. Anim. Sci. 76:299-308.

Clary, E. M., R. T. Brandt Jr., D. L. Harmon, and T. G. Nagaraja. 1993. Supplemental fat and ionophores in finishing diets: Feedlot performance and ruminal digesta kinetics in steers. J. Anim. Sci. 71:3115-3123.

Depenbusch, B. E., E. R. Loe, M. J. Quinn, M. E. Corrigan, M. L. Gibson, K. K. Karges, and J. S. Drouillard. 2008. Corn distillers grains with solubles derived from a traditional or partial fractionation process: Growth performance and carcass characteristics of finishing feedlot heifers. J. Anim. Sci. 86:2338-2343.

Duffield, T. F., J. K. Merrill, and R. N. Bagg. 2012. Meta-analysis of the effects of monensin in beef cattle on feed efficiency, body weight gain, and dry matter intake. J. Anim. Sci. 90:4583-4592.

Elam, N. A., J. F. Gleghorn, J. D. Riveria, M. L. Galyean, P. J. Defoor, M. M. Brashears, and M. Younts-Dahl. 2003. Effects of live cultures on Lactobacillus acidophilus (strains NP45 and NP51) and Propionibacterium freudenreichii on performance, carcass, and intestinal characteristics, and Escherichia coli strain O157 shedding of finishing beef steers. J. Anim. Sci. 81:2686-2698.

Elanco Animal Health. 2012. Effect of Rumensin and Tylan fed separately or in combination on feed efficiency and liver abscesses and the resulting effects on carcass characteristics of feedlot steers. Rumensin and Tylan Research Brief 1. Elanco Study No. CR-0509. Accessed Aug. 26, 2016. http://www.elanco.us/pdfs/rumensin-andtylan-research-brief-1.pdf.
FASS. 2010. Guide for the Care and Use of Agricultural Animals in Agricultural Research and Teaching. 3rd ed. FASS Inc., Champaign, IL.

Feye, K. M., K. L. Anderson, M. F. Scott, D. L. Henry, K. L. Dorton, B. E. Depenbusch, and S. A. Carlson. 2016. Abrogation of Salmonella and E. coli O157:H7 in feedlot cattle fed a proprietary Saccharomyces cerevisiae fermentation prototype. J. Vet. Sci. Technol. 7:350 http:// dx.doi.org/https://doi.org/10.4172/2157-7579.1000350.

Laudert, S. B., and G. Vogel. 2004. Tech Talk. Tylan Efficacy-A 40-trial summary. Accessed Nov. 6, 2015. http://www.elanco.us/pdfs/ tylan-efficacy_40-trial-tech-talk-ai11115_ruty19332.pdf.

Long, P. L., and T. K. Jeffers. 1982. Studies on the stage of action of ionophorus antibiotics against Eimeria. J. Parasitol. 68:363-371.

Meyer, N. F., G. E. Erickson, T. J. Klopfenstein, J. R. Benton, M. K. Luebbe, and S. B. Laudert. 2013. Effects of monensin and tylosin in finishing diets containing corn wet distillers grains with solubles with differing corn processing methods. J. Anim. Sci. 91:2219-2228.

Nagaraja, T. G., and M. M. Chengappa. 1998. Liver abscesses in feedlot cattle: A review. J. Anim. Sci. 76:287-298.

Peterson, R. E., T. J. Klopfenstein, G. E. Erickson, J. Folmer, S. Hinkley, R. A. Moxley, and D. R. Smith. 2007. Effect of Lactobacillus acidophilus strain NP51 on Escherichia coli O157:H7 fecal shedding and finishing performance in beef feedlot cattle. J. Food Prot. 70:287-291.

Reinhardt, C. D., and M. E. Hubbert. 2015. Control of liver abscesses in feedlot cattle: A review. Prof. Anim. Sci. 31:101-108.

Stock, R. A., S. B. Laudert, W. W. Stroup, E. M. Larson, J. C. Parrott, and R. A. Britton. 1995. Effect of monensin and monensin and tylosin combination on feed intake variation of feedlot steers. J. Anim. Sci. 73:39-44.

Swyers, K. L., J. J. Wagner, K. L. Dorton, and S. L. Archibeque. 2014. Evaluation of Saccharomyces cerevisiae fermentation product as an alternative to monensin on growth performance, cost of gain, and carcass characteristics of heavy-weight yearling beef steers. J. Anim. Sci. 92:2538-2545.

US Food and Drug Administration. 2015. FACT SHEET: Veterinary Feed Directive Final Rule and Next Steps. Accessed Aug. 26, 2016. http://www.fda.gov/AnimalVeterinary/ DevelopmentApprovalProcess/ucm449019.htm.

Wagner, J. J., T. E. Engle, C. R. Belknap, and K. L. Dorton. 2016. Meta-analysis examining the effects of Saccharomyces cerevisiae fermentation products on feedlot performance and carcass traits. Prof. Anim. Sci. 32:172-182. 